\title{
RECOGNIZING THE OTHER AS A TEST OF EUROPEANNESS THE VALUE-BASED FOUNDATIONS OF INDIVIDUAL REFLEXIVITY IN THE ERA OF LATE MODERNITY
}

\author{
Zoltan GRUNHUT \\ Centre for Economic and Regional Studies \\ Budapest/Hungary \\ grunhut@rkk.hu
}

\begin{abstract}
The paper both theoretically and empirically examines the interrelationship between the act of othering (i.e. self-identification via distantiation from the 'Other') and the attachment to Europe, while it also addresses the value-based ontological foundations of these epistemologically relevant and praxis-related features. Late Modernity is proposed as a general framework that can hold together these components conceptually. The empirical findings are about $18 \mathrm{EU}$ member states; data were obtained from the European Social Survey (2018). As a general conclusion the paper stresses that people who prefer the relative importance of values about diversity and self-transcendence, they are more open towards the 'Other', while they are more attached to Europe as well.
\end{abstract}

\section{Keywords}

Europeanness; European Social Survey; late Modernity; othering; Shalom H. Schwartz; values 


\section{INTRODUCTION}

The paper theoretically links three notions, namely 'othering', 'Europeanness', and 'values' under the conceptual grand-narrative of Late Modernity, while it also empirically examines the interrelatedness of these aspects. From the perspective of the self the act of othering is in fact 'becoming', i.e. a selfidentification through distantiation from the 'Other'. ${ }^{1}$ In line with this, the existential self-understanding of 'being' is also about the 'otherness' of the Other. For the emancipation of the self, however, the Other needs to be liberated from this objectified status since it has an alienating impact on the self as well. Accordingly, without the recognition of the Other's subjectivity, the self cannot unfold its own uniqueness either; it just pursues representations from a contemplative and detached position. Thus, the self's autonomous freedom is existentially connected to the acknowledgement of the Other's freedom. Insofar as the political project of Europe is both about institutional multilateralism and cosmopolitan multiculturalism, Europeanness as a normative-cognitive ideational substance and a pool of praxes is strongly related to the above described act of recognizing the Other. People of Europe are very different respective to their collective customs, norms, and conventions, thus according to their culturally and linguistically framed social structures. Yet, people of Europe are also very different regarding to their individualities. So, Europe is diverse in many ways, nevertheless as an entity it is actually based on the recognition of these individual and social diversities. In the era of Late Modernity the acknowledgement of these diversities is even more urgent as the parallel processes of globalization and localization generate institutional abstractions, which question the logics and semantics of particular cultures, and promote, instead, universalism. Traditional references are not valid any longer, therefore people need to abandon their pattern-based routines and rely on their reflexive

1 The concept of the Other traces back to Hegel's master-slave dialectical relation (see: Brons 2015). Later the approach was further developed especially in French philosophy, most importantly by theoretical contributions from Sartre, de Beauvoir, Levinas, Kristeva, Derrida, and Lacan. 
capacities and critical agencies. This process indicates individualization, i.e. the emergence of unconstrained individual subjectivities. Accordingly, the unstoppable, at most from a traditional perspective refutable Late Modernity is in itself facilitating European togetherness based on the recognition of all subjects' uniqueness. Europeanness, however, with its epistemologically relevant and praxis-related content could be unfolded just if a subjective ontological foundation supports it. These underpinning basics are the values, i.e. the emotionally driving and rationally justifying standards and criteria of one's constituted self. Values as ontological beliefs enable the individual agents to develop their reflexive capacities and critical agencies necessitated by the institutional abstractions of Late Modernity. In light of this argument, the paper claims and empirically inquires that the recognition of the Other is associated with an attachment to Europe, while both of these features are related to a certain individual value-set respects diversity.

\section{EUROPE IN THE ERA OF LATE MODERNITY}

Late Modernity as a concept is mostly linked to two distinguished thinkers, Anthony Giddens and Ulrich Beck (Beck et al. 1994). Their starting point is that Modernization is not a linear process, i.e. a continuous progression from one stage to another, but rather a series of shifts between transformations and restorations in the social realm. It is due to the context of structuration, which claims that institutions and agents are endlessly shaping and reshaping each other (Giddens 1984). Accordingly, institutions have framing capacities, yet agents also have critical and reflexive subjectivity to overcome these constraints. Furthermore, this spontaneous actorness of the individuals is significantly unfolding in Late Modernity; actually, this is the generative feature of this era (Giddens 1991). In pre-modern times religious references as one-dimensional logics and semantics strongly influenced subjects' ideas (way of thinking) and praxes (way of doing things), while these constraints also forced rigidly understood roles and superior-inferior statuses on individual agents and their interactions. Then in Classic Modernity, due to the Enlightenment and after the 
emergence of the Westphalian world order, religious references were challenged by secularism and national ethoses. In line with this tendency, nation-states cultivating and protecting national cultures and heritages, using national languages, and providing public services among them most importantly public education and home front defense in order to socialize individuals through the 'in-group'-'out-group' perspective became the new the institutional foundations (cf. Anderson 1983). Hence, Classic Modernity is both conceptually and empirically grasped through the lenses of rationalization and bureaucratization (Weber), through the process of extension from community (Gemeinschaft) to society (Gesellschaft) (Tönnies), or from mechanical to organic solidarity (Durkheim), and through an increasing functional (Parsons), systemic (Luhmann), and field-related (Bourdieu) differentiations of societies (Giddens 1995). What all these approaches have in common is that they unanimously favor structures in their theoretical arguments against individual actors, which latters are considered as agents adapt their ideas and praxes to external patterns. Late Modernity, instead, is about a shift towards autonomous agency since certain interrelated trends are heavily undermining particular cultures in this era (Beck et al. 2003). These trends are the pervasiveness of interdependencies, the penetration of uncertainties, and the expansion of individualization, which three phenomena could be seen as institutional abstractions (Giddens 1990).

Already from the end of the $2^{\text {nd }}$ World War, more obviously from the ' 60 s and '70s, and particularly since the dissolution of the bipolar system, a parallel globalization and localization drive our world. This constellation means that everything, in fact, has a dual global and local relevancy, since structural interconnectedness is inexorably pervading from political, economic and security ties, through energy-supply, info-communication and environmental challenges, to technological development and evolution of digitalized megasystems (Giddens 1990). This trend is creating different kinds of globally expansive and locally palpable interdependencies, like the extreme division of labour, international product- and service-lines, as well as robotized and automatized supply-systems, not to mention the worldwide flows of goods, capitals, and information, on the one hand, while also threats and hazards like terrorism, extremism, international crime, illegal migration, global warming, 
health diseases, etc., on the other hand (Beck 1992). What is global becomes local, and what is local turns to be global at the same time, which interrelatedness is undermining the reference value of particular logics and semantics (Giddens 1999). Agents' intersubjective interactions are also more and more relating to anonymous and faceless partners in the virtual space, or even being replaced by subjective ones with 'smart technologies'. Therefore, a pressuring anxiety emerges about how to understand, translate, interpret, and react to these penetrating impulses, and about how can the filters of particular cultures decode and recode these impacts. Individuals experience that somehow their 'inhabited world' is expanding and shrinking simultaneously; while the various flows are radically widening local contexts, without common references the diverse subjective approaches about how to reflect on these impulses undermine the sense of belonging to a certain community.

These globally-locally relevant interdependencies, due to the flows, are creating different kinds of uncertainties, and to concern with these risks is rather an individual than a collective task since particular logics and semantics cannot provide adequate patterns any longer (Beck 1992). Individual agents, thus, have to rely on their reflexive and critical actorness, and the more they expand their autonomous and spontaneous subjectivity, the more traditional references are falsified (Beck 1999). However, individualization is going beyond reflecting on interdependencies. If cultural logics and semantics are dubious, then these patterns cannot give reliable meanings to social statuses, roles, positions, bonds, relationships, and interactions either. This leads to a series of shifts. First of all, patriarchal structures legitimizing Man's dominance over Woman are unveiled to be male chauvinist and sexist (Beck and Beck-Gernsheim 1995). The 'othering' of women by biased ideas, such as they are physically weaker, more sensitive, more affective, more caring, more romantic, less competitive, less autonomous, more aesthetic-minded, etc., is a traditional semantic that hardly keeps its reference value in Late Modernity. This shift has fundamental impacts on women's lifestyles from relationships (roles in family, status of marriage, courtships and friendships), through education and career (studies, positions, employment, entrepreneurship), to consumption and public-political engagement. This leads to the de- and reconstruction of the status of loving 
relationships (Giddens 1992). Neither the traditional narratives (romantic bond, being 'stick together forever', establishing a 'common life and future', etc.), nor the legal interpretation (marriage as a pact) matter as basic references. Instead, the aspects of intimacy, togetherness, equality, honesty, bond of communion, mutuality, respect, giving freedom and space, providing a supportive and inspirational atmosphere to each other are becoming essential features of a courtship/loveship (Beck and Beck-Gernsheim 1995). The sexual orientation of the parties is irrelevant, the traditional model is not universal any longer. The emphasis is on the quality of the relationship; if it can or cannot safeguard an intimate connectedness for the partners to live a peaceful life in an era full of contingencies (Giddens 1992). In line with this, break-ups are not considered as failures. On the contrary, to cut short an unhappy relationship is a reflexive action. The concept of marriage is changing as well. It is more and more a tendency that not just men but also women - irrespective to age - enjoy the autonomy from social pressures to be single. Couples are together for years without being married. Frequently they are not keeping a common household or living in the same area. Long-distance relationships are thriving, more commonly between people with very different national and cultural backgrounds (Beck and Beck-Gernsheim 2002). Understanding about divorcement is also different than it used to be. If a marriage is not working, then its legal status cannot hold it together either, so the procedure of getting divorced is demanded to be faster and easier. Accordingly, contracts about separated incomes, bank accounts, and properties are becoming usual features of a marriage. Of course, due to these tendencies family as a basic social unit is perceived through a new lens as well. The traditional model of father, mother and $\mathrm{kid}(\mathrm{s})$ does not have a reference value any more. On the one hand, gay and lesbian couples have the same rights as heterosexual ones (to marry, to adopt, to have joint loans and credits, to enjoy family-related social benefits and subsidies, etc.) in more and more societies, while on the other hand, single-parent families are widely accepted and respected both socially and institutionally. The roles of family members are also in a change. Neither based on gender, nor due to traditional family functionality there should not be a distinction between 'breadwinning' and 'childrearing-housekeeping' tasks. Obviously, 'strong ties', 
i.e. the intensiveness of bonds between different generations of an extended family (for instance, to have a common household, to live close to each other, to ask for daily favors, to share certain costs or loans, etc.) is decreasing as well; nuclear families, instead, are more relying on formal relations with various entities.

In light of this argument, the parallel globalization and localization of interdependencies infuse everyday interactions with relevant uncertainties. Subjects cannot follow their routines based on particular patterns as these cultural references are inadequate to interact upon due to their static nature constrains individual agency (Beck 1992). Subjects, thus, have to develop their reflexive and critical capacities, which process leads to the expansion of autonomous and spontaneous actorness. This further weakens the relevancy of traditional logics and semantics, i.e. societies become more unpredictable, more pluralistic, more heterogeneous, and more diverse since individual subjectivity is flourishing (Giddens 1990). Dealing with uncertainties, thereby, creates further contingencies. Although subjects still strive to apply customized ideas and praxes in their interactions, as Giddens says, to 'colonize' their future in order to make it foreseeable, yet the reliability of these routines, so to achieve an ontological security, is rather up to a dynamically adaptive reflexive and critical agency than to follow particular references (Giddens 1991). As this ontological security is both about a feeling of stability and about foundations of one's identity, therefore in Late Modernity subjects have to accept on the one hand, that stability is not based on solid logics and semantics but it derives from an openness to continuous changes, while on the other hand, they need constantly deconstruct and reconstruct their selves accordingly. As everyday interactions are also 'trials', individual agents, thus, narratively and performatively constitute their subjectivity through these social activities (Giddens 1991). In light of this, they gain and grasp reflexive and critical capacities and knowledge through interactions, most notably with their intimate partners. As these relationships supposed to be more trusting, subjects, thereby, first learn reflexivity and critical agency with their loved ones, with their best friends, and with their close-knit relations (Beck and Beck-Gernsheim 2002). Showing recognition, respect, tolerance, solidarity, and empathy towards others, just as 
pursuing equality, justice, deliberative consensus, and peaceful reconciliation of conflicts derive from the subjects' similarly working intimate relationships. Consequently, reflexivity and critical agency have an individual, a social, and an institutional level as well. The very latter should be understood as the reflection of institutions; if the subjects are reflexive, then their structural frameworks will change accordingly.

Through this lens the political project of 'Europe' could be seen as a series of reflexive institutional efforts in the era of Late Modernity (Beck and Grande 2007). The EU is neither about supranationalism, i.e. an evolution of European superstructures leading towards a post-Westphalian constellation, nor only about inter-governmentalism, or multi-level, multi-sector, and multi-actor partnerships, since neither of these approaches would progress beyond the unequivocal 'either/or' logics and semantics. Europe should be constructed, instead, along the 'both/and' principle, which is the only alternative to reflexively and critically overshadow the self/in-group-other/out-group mechanism of distantiation (Beck 2006). Europe in the era of Late Modernity is based on three distinguished references. Pan-relationalism is the recognition of an existential attachment among subjects and related to the subjects-objects visà-vis nexuses. Anti-representationalism is the understanding that nothing is represented to the individual agents, but everything is presented/constructed by them, so both actorness related to the framing structures is possible and subjects' embeddedness into their objective, natural, and social surroundings is existentially indispensable. And finally anti-essentialism highlights that there are no essential Truths, only subjective beliefs justified through deliberative communications. All these references undermine the 'either/or' particular logics and semantics, while they promote, instead, the 'both/and' principle questions the validity of all kinds of one-dimensional framings, monolithic interpretations, and mono-linguistic translations (Beck 1998).

Accordingly, Europe as a reflexive institutional entity supports gender equality against patriarchal structures, and equal rights for all subjects irrespective to their ethnic, religious, or political backgrounds and sexual orientation. It strives for the free flow of people, information, material and immaterial capitals, goods, and services. It contributes to the culture of deliberative communications by 
encouraging civil engagement, safeguarding transparency, and preventing ideational hegemonies through free press and unrestricted expression of subjective perspectives (Beck and Grande 2007). Europe facilitates social integration, acceptance, and solidarity against exclusionist marginalization and scapegoating accusations. It favors interdisciplinary scientization against monoscopic expertization, and it prefers arguments of truth-candidates searching for consensual justice against findings reveal fixed and unquestionable Truths (Beck 2005). Europe in the era of Late Modernity has to follow this cosmopolitan path otherwise it would fall back to the constellation of 'either/or' logics and semantics entail disintegration and the re-emergence of traditional cultures.

\section{VALUES AS ONTOLOGICAL FOUNDATIONS}

According to the above-described theoretical argument, the agents' reflexive and critical actorness embraces specific ideational substances and praxes adequate to the abstraction processes of Late Modernity. This actorness, thereby, refers to epistemological level and action-related features. Compare to these aspects of agency, the feeling of ontological security, theorized by Giddens as a routinized individual stance provides stability and reliability to the subject, should be understood as something more foundational. The constituted self's multilayered subjectivity originates back to this stance that ontologically enables the agent to construct certain epistemologically relevant ideas, and based on these cognitive-normative understandings to apply adequate praxes. This basic stance comprises values, which are both emotionally affective beliefs and rationally consistent justifications serve as guidelines. These values have different meanings, some of them are in complementing, some rather in conflicting relation with each other. Irrespective to cultures, these meanings are constant, however the subjects' own sets of values, their own preferences are culturally framed (Schwartz and Bilsky 1990). To put it in another way, values are abstract and general, but the subjective set of values is always particular. This 
constellation makes us individually unique, yet also embedded into a sociocultural and socio-moral environment.

And exactly this is the main challenge of Late Modernity, insofar as the abstraction processes of this era undermine the traditional cultures provide references, such as norms, codes, customs, and framing narratives for subjects to create their sets of values. As these cultural semantics and logics are getting to be more and more questioned subjects' anxiety about their ontological security is growing. They need to un-build and re-build their sets of values in order to make their preferences more adequate to the cosmopolitan shifts of Late Modernity. They need to re-constitute their selves in order to be able for reflexive and critical agency allows Gestalt-switches (complete change about one's way of thinking and doing things). And they need to deconstruct and reconstruct their individual ideas and praxes in order to overcome the everyday uncertainties of intersubjective and subjective interactions. Without stable references subjects need to rely on themselves. Those who are able to proceed on this cosmopolitan path can adapt to Late Modernity easier, while those who have serious setbacks and struggles are rather yearning for the recovery of traditional semantics and logics. Accordingly, Late Modernity urges subjects, all around the world and irrespective to their cultural environment, to redefine their epistemologically relevant ideas and action-level praxes, but more importantly to redesign their sets of values since those who are able to ontologically rely on an individual stance enables them for continuous reflexive and critical de- and reconstruction of their selves could deal with the meta-shifts of this era much more adequately. As Late Modernity is really about dialectical meta-shifts. It is not just proceeding Classic Modernity with something new, globalized and universal, but still static structural framing. On the contrary, it is a dynamic progressiveness without fixed references. Everything turns to be fluid, infinite and boundless underpinned by the 'both/and' principle of a future-oriented and recognition-based subjective agency respects existential togetherness. This is why it is important to understand individual perceptions, interpretations, attitudes, and behaviours from the perspective of values, as the latters are the ontological foundations. 
There are many contemporary value-theories in the literature, yet probably the most elaborated one is the concept of Basic Human Values proposed by Shalom H. Schwartz (1992, 2005, 2006, 2012). It purposefully strives to synthesize or at least consider other relevant approaches, while it is continuously revised through empirical inputs as well. Schwartz highlights that values are referring to three universal requirements: (1) about one's biological needs, (2) about coordination of social interactions, and (3) about survival needs related to welfare and well-being of different social groups. As it clearly seems these requirements are embracing both individual and more extended collective needs, which suggests that subjects are individual selves existentially embedded into their social surroundings. Beside the requirements Schwartz also identifies six universal features of values based on previous concepts. He underlines that (1) values are both rational justifications and emotional beliefs; (2) values are motivational sources for desired goals (what to achieve); (3) but values are also standards and criteria with normative contents (how to achieve objectives); (4) values are abstract in their natures, so they transcend particular situations and interactions; (5) one's individual set is a dynamically constructed preference, therefore values are ranked according to subjectively understood relative importance; and finally (6) an individual agent's ideas and praxes are always underpinned by more than one value. Schwartz (2006) distinguishes 10 types of the Basic Human Values:

1. Self-Direction. It represents the desire of experiencing autonomy about one's own life, independence and innovativeness both about thoughts and actions. It is describable by the notions of choosing, creating, creativity, curiosity, and exploring.

2. Stimulation. It traces back to the desire of enjoying changes and new, untried paths in one's own life. It refers to the inspiring excitement of taking risks and pursuing novelties and challenges. It also represents the motivation of breaking with routines and habits.

3. Hedonism. It is identifiable as pleasure and sensuous gratification for oneself. 
4. Achievement. It is understandable as the ambition for personal success through demonstrating competence according to social standards.

5. Power. Schwartz describes this value as the desire of well-acknowledged social status and prestige, as well as control or dominance over people and various resources.

6. Security. It is identifiable as a desired goal to achieve existential - both material and physical - safety; a harmony of personal relationships contributes to the self's emotional and mental balance; in a more extended sense, to enjoy social stability.

7. Conformity. It is a motivation of being loyal, adjusted, and accommodated to social norms and expectations, and to restrain from actions, inclinations, and impulses likely to harm these collective references.

8. Tradition. It is understandable as respect, commitment, and acceptance of the customs, codes, taboos, social rules, collective knowledge, experiences, and narratives represented in the traditional logics and semantics of one's cultural surroundings.

9. Benevolence. It is about preserving and enhancing the welfare of those 'in-group' subjects with whom one is in frequent, close-knit, and/or more intimate personal contact.

10. Universalism. It inspires to respect the importance of others' welfare and well-being (solidarity and equality), to appreciate the peaceful and consensus-oriented reconciliation of social problems (peace and justice), to acknowledge the relevancy of deliberative pluralism (democracy), to be open towards otherness and diversity (tolerance), and to protect the natural environment.

These basic values can be grouped into two main categories: the first five have rather self-oriented, more individual-centered meanings (the subject in contrast to others as a unique agent), while the second half embraces values with rather collective connotations (the subject among others with respect to the references, patterns, interests, diversity, etc. of these social groups). Notwithstanding, for Schwartz to differentiate the values into a 'four dimensions-two axes' model is more crucial. These dimensions are Openness to change vs. Conservation on one 
axe, and Self-enhancement vs. Self-transcendence on the other axe. Openness to change embraces the values of Self-direction and Stimulation, while Conservation as an oppositional dimension comprises Security, Conformity, and Tradition. On the other axe Self-enhancement, based on Achievement and Power, stands against Self-transcendence, which is built on Universalism and Benevolence. Hedonism is not clearly placed in this model, so respective to this single value its individual meaning is rather more important to note.

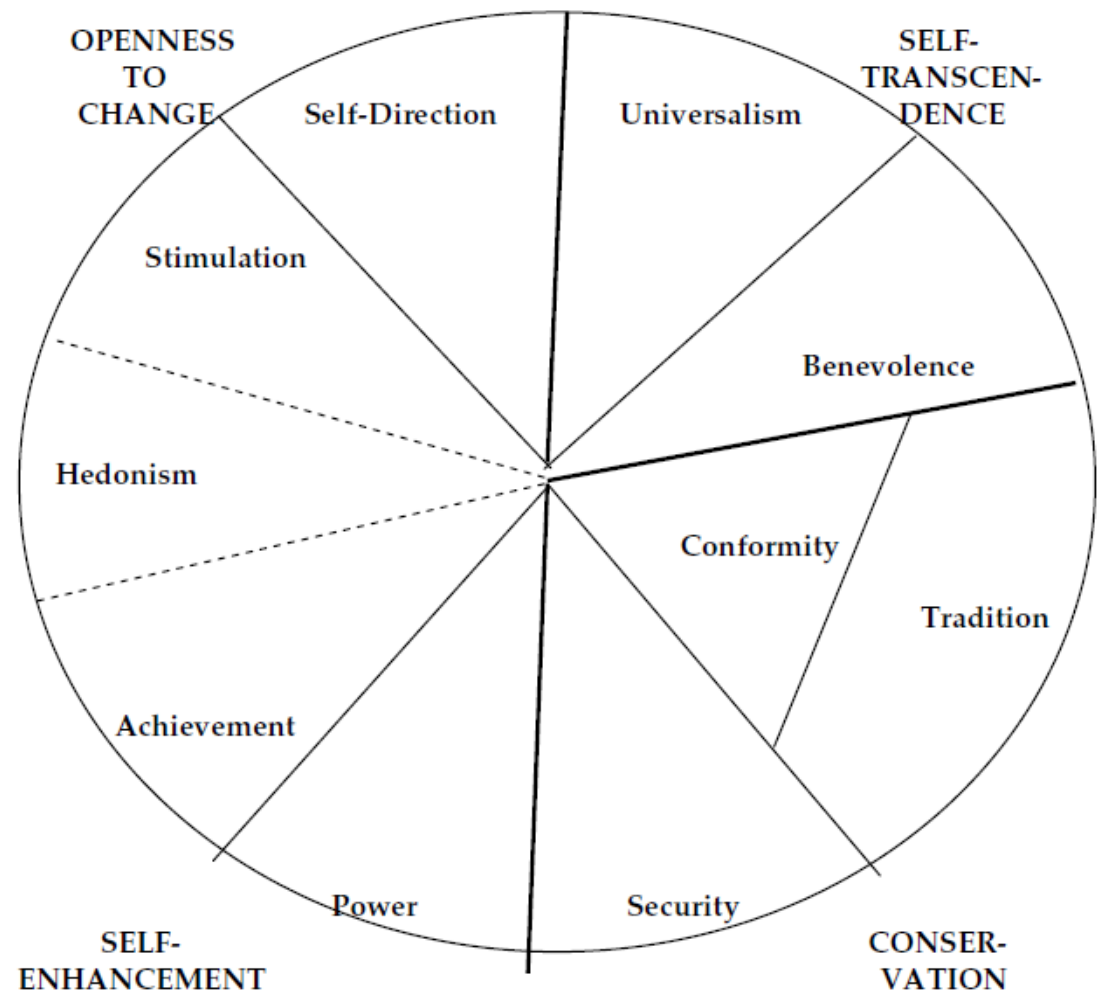

Figure 1. The Schwartz model

Source: Schwartz 2001, 270. 
There is dynamic interrelation among these values. Based on Figure 1 this theoretical inner-mechanism is easier to understand, insofar as compare to the subject's most preferred value the others' relative importance on both directions, i.e. starting with either left or right on the circle to the other end point, is continuously decreasing. This is how one's individual set of values is working as an ontological foundation frames epistemologically relevant ideas and actionrelated praxes through the lens of a subjective preference of values. In line with this, not one principal value, but always a combination of values defines one's ideational substances and practices. It is also important to note that according to this circle-based inner-mechanism certain values grouped into different dimensions are closer to each other than other values. For instance, Selfdirection is in the same dimension with Stimulation, yet closer to Universalism than to Benevolence or Hedonism. This constellation has a theoretical function, inasmuch values next to each other in the circle always have some common meanings. In light of this, Schwartz highlights that (1) Power and Achievement both emphasize social superiority and esteem; (2) Achievement and Hedonism both are concerned with self-indulgence; (3) Hedonism and Stimulation both entail a desire for affectively pleasant arousal; (4) Stimulation and Self-direction both involve intrinsic motivation for mastery and openness to change; (5) Selfdirection and Universalism both express reliance on one's own judgment and comfort with the diversity of existence; (6) Universalism and Benevolence both are concerned with enhancement of others and transcendence of selfish interests; (7) Tradition and Conformity both stress self-restraint and submission; (8) Conformity and Security both emphasize protection of order and harmony in relations; and (9) Security and Power both stress the attempt to avoid or overcome the threat of uncertainties by controlling relationships and resources (cf. Schwartz 1992, 14-15). 


\section{OTHERING, EUROPEANNESS, AND VALUES. THE EMPIRICAL FINDINGS}

As it was already said above, the empirical part of the paper, on the one hand, examines the interrelationship between the acceptance of the Other and the attachment to Europe. As both of these ideational substances refer to the subjects' ability to abandon traditional logics and semantics as references, and rely, instead, on their reflexive capacities and critical agencies required in the era of Late Modernity, therefore the paper assumes a positive association between the two features. Nonetheless, both recognizing the Other and appreciating Europeanness are connected to epistemologically relevant and praxis-related features have to be ontologically supported by a certain individual set of values. Respective to these ontological foundations, on the other hand, the paper assumes that those subjects who prefer the relative importance of values about diversity and self-transcendence, i.e Universalism, Benevolence, and Selfdirection, they are more open towards the Others, while they are more attached to Europe as well.

Data for the empirical inquiry were obtained from the $8^{\text {th }}$ wave of the European Social Survey (ESS 2016). ${ }^{1}$ As a first step a 6-items-based composite index about othering was elaborated. Using the scales of the questionnaire-items the optional answers were categorized and addressed by the reference values of 0,1 or 2 (Table 1). Then based on their subjective perceptions individual respondents were distinguished into three distinct groups: 'exclusionist', 'ambivalent', and 'inclusionist' (Table 2).

1 The ESS is an open-source, academically driven, cross-national, bi-annual, representative survey that has been conducted across Europe since 2001. The survey measures the attitudes, beliefs and behaviour patterns of diverse populations; respective to the 8 th wave this means more than 40 thousands respondents from more than 20 countries. For this investigation only the EU member states' data were used. 
Table 1. The composite index of othering

\begin{tabular}{|c|c|c|c|}
\hline \multirow[t]{2}{*}{ Variables } & \multicolumn{3}{|c|}{ Reference values } \\
\hline & 0 & 1 & 2 \\
\hline $\begin{array}{l}\text { When jobs are scarce, men } \\
\text { should have more right to a } \\
\text { job than women. }\end{array}$ & $\begin{array}{l}1 \text { - Agree } \\
\text { strongly } \\
2 \text { - Agree }\end{array}$ & $\begin{array}{l}3 \text { - Neither } \\
\text { agree nor } \\
\text { disagree }\end{array}$ & $\begin{array}{l}4- \\
\text { Disagree } \\
5 \text { - } \\
\text { Disagree } \\
\text { strongly }\end{array}$ \\
\hline $\begin{array}{l}\text { Gay men and lesbians } \\
\text { should be free to live their } \\
\text { own life as they wish }\end{array}$ & $\begin{array}{l}4 \text { - Disagree } \\
5 \text { - Disagree } \\
\text { strongly }\end{array}$ & $\begin{array}{l}3 \text { - Neither } \\
\text { agree nor } \\
\text { disagree }\end{array}$ & $\begin{array}{l}1 \text { - Agree } \\
\text { strongly } \\
2 \text { - Agree }\end{array}$ \\
\hline $\begin{array}{l}\text { Gay male and lesbian } \\
\text { couples should have the } \\
\text { same rights to adopt } \\
\text { children as straight couples. }\end{array}$ & $\begin{array}{l}4 \text { - Disagree } \\
5 \text { - Disagree } \\
\text { strongly }\end{array}$ & $\begin{array}{l}3 \text { - Neither } \\
\text { agree nor } \\
\text { disagree }\end{array}$ & $\begin{array}{l}1 \text { - Agree } \\
\text { strongly } \\
2 \text { - Agree }\end{array}$ \\
\hline $\begin{array}{l}\text { Would you say it is generally } \\
\text { bad or good for [country]'s } \\
\text { economy that people come } \\
\text { to live here from other } \\
\text { countries? ['0' means 'Bad } \\
\text { for the economy' whereas } \\
\text { '10' means 'Good for the } \\
\text { economy'] }\end{array}$ & $\begin{array}{l}\text { Scale values } \\
\text { from } 00 \text { to } 03\end{array}$ & $\begin{array}{l}\text { Scale values } \\
\text { from } 04 \text { to } 06\end{array}$ & $\begin{array}{l}\text { Scale } \\
\text { values } \\
\text { from } 07 \text { to } \\
10\end{array}$ \\
\hline $\begin{array}{l}\text { Would you say that } \\
\text { [country]'s cultural life is } \\
\text { generally undermined or } \\
\text { enriched by people coming } \\
\text { to live here from other } \\
\text { countries? ['0' means } \\
\text { 'Cultural life undermined' } \\
\text { whereas ' } 10^{\prime} \text { means 'Cultural } \\
\text { life enriched'] }\end{array}$ & $\begin{array}{l}\text { Scale values } \\
\text { from } 00 \text { to } 03\end{array}$ & $\begin{array}{l}\text { Scale values } \\
\text { from } 04 \text { to } 06\end{array}$ & $\begin{array}{l}\text { Scale } \\
\text { values } \\
\text { from } 07 \text { to } \\
10\end{array}$ \\
\hline
\end{tabular}




\begin{tabular}{|c|c|c|c|}
\hline $\begin{array}{l}\text { Is [country] made a worse or } \\
\text { a better place to live by } \\
\text { people coming to live here } \\
\text { from other countries? ['0' } \\
\text { means 'Worse place to live' } \\
\text { whereas ' } 10 \text { ' means 'Better } \\
\text { place to live'] }\end{array}$ & $\begin{array}{l}\text { Scale values } \\
\text { from } 00 \text { to } 03\end{array}$ & $\begin{array}{l}\text { Scale values } \\
\text { from } 04 \text { to } 06\end{array}$ & $\begin{array}{l}\text { Scale } \\
\text { values } \\
\text { from } 07 \text { to } \\
10\end{array}$ \\
\hline
\end{tabular}

Source: Author's own elaboration based on ESS8 questionnaire

As regards to the categorical reference values presented in Table 1 each respondent's cumulated index-value about othering could be between 0 and 12 . Table 2 shows how the respondents were grouped according to their cumulated index-value.

Table 2. Groups according to the praxis of othering

\begin{tabular}{|c|c|}
\hline Group & Cumulated index-value \\
\hline Exclusionist & from 0 to 4 \\
\hline Ambivalent & from 5 to 7 \\
\hline Inclusionist & from 8 to 12 \\
\hline
\end{tabular}

Source: Author's own elaboration based on ESS8 questionnaire

Table 3 illustrates the percentage of each group respective to the EU member states in the total sample. As it is identifiable more than $53 \%$ of the respondents belong to the inclusionist group. $29.7 \%$ are ambivalent, while $17 \%$ are exclusionist.

Table 3. Percentage of each group in the total EU sample $(\mathrm{N}=31987)$

\begin{tabular}{|c|c|c|c|c|}
\hline \multicolumn{2}{|c|}{} & Frequency & $\%$ & Valid \% \\
\hline \multirow{7}{*}{ Valid } & Exclusionist & 5425 & 15.3 & 17.0 \\
\cline { 2 - 5 } & Ambivalent & 9498 & 26.8 & 29.7 \\
\cline { 2 - 5 } & Inclusionist & 17064 & 48.1 & 53.3 \\
\cline { 2 - 5 } & Total & 31987 & 90.2 & 100.0 \\
\hline Missing & System & 3463 & 9.8 & \\
\hline Total & 35450 & 100.0 & \\
\hline
\end{tabular}

Source: Author's own elaboration based on data from ESS8 
Table 4 represents the percentage of each groups according to the examined EU member states. There are important findings to note. For instance, in Hungary more than $50 \%$ of the population belongs to the exclusionist group. The proportion of exclusionists are also quite high in Italy (35.1\%), in Lithuania $(34.6 \%)$, in the Czech Republic (30.4\%), in Slovenia (27.1\%), and in Estonia (27\%), while it is around one-fifth of the population in Poland and in Austria, 20.9\% and $19 \%$ respectively. On the contrary, the proportion of inclusionist people is very significant in Sweden (82.8\%), in the Netherlands (79.3), in Spain (72.9\%), in the United Kingdom (71.7\%), in Finland (71\%), while it is above the 50\% percent also in Belgium (66.4\%), in Germany (66.2\%), in Portugal (65.9\%), and in France $(57.6 \%)$. The inclusionist group in Hungary is only $13.6 \%, 20 \%$ in Lithuania, and $24.4 \%$ in the Czech Republic. The proportion of ambivalent people are relevant in the latter two countries, $45.4 \%$ and $45.2 \%$ respectively, while it is $40.5 \%$ in Poland. In general, it can be noticed that the post-socialist countries are rather exclusionist and ambivalent, while the Western European ones are rather inclusionist. Among the latter countries Italy undoubtedly, but also Austria are sliding towards exclusionist tendencies.

Table 4. Percentage of each group according to EU member states (\%) $(\mathrm{N}=31987)$

\begin{tabular}{|c|c|c|c|}
\hline & Exclusionists & Ambivalent & Inclusionist \\
\hline Sweden & 3.1 & 14.1 & 82.8 \\
\hline Netherlands & 2.7 & 18.0 & 79.3 \\
\hline Spain & 4.9 & 18.2 & 76.9 \\
\hline Ireland & 6.4 & 20.7 & 72.9 \\
\hline United Kingdom & 6.2 & 22.1 & 71.7 \\
\hline Finland & 6.8 & 22.2 & 71.0 \\
\hline Belgium & 6.6 & 27.0 & 66.4 \\
\hline Germany & 8.0 & 25.8 & 66.2 \\
\hline Portugal & 8.5 & 25.6 & 65.9 \\
\hline France & 11.6 & 30.8 & 57.6 \\
\hline Austria & 19.0 & 33.9 & 47.1 \\
\hline
\end{tabular}




\begin{tabular}{|c|c|c|c|}
\hline Slovenia & 27.1 & 33.7 & 39.2 \\
\hline Poland & 20.9 & 40.5 & 38.6 \\
\hline Estonia & 27.0 & 37.2 & 35.8 \\
\hline Italy & 35.1 & 36.3 & 28.6 \\
\hline Czech Republic & 30.4 & 45.2 & 24.4 \\
\hline Lithuania & 34.6 & 45.4 & 20.0 \\
\hline Hungary & 51.5 & 34.9 & 13.6 \\
\hline
\end{tabular}

Source: Author's own elaboration based on data from ESS8

In the following the paper examines the relationship between othering and Europeanness by testing the attachment to Europe in the exclusionist, ambivalent, and inclusionist groups. Europeanness is addressed by the variable of 'How emotionally attached do you feel to Europe?' Respondents could describe their perceptions by using a 0-10 scale where ' 0 ' means 'Not at all emotionally attached' and '10' refers to 'Very emotionally attached'. As it is displayed on Table 5 Europeanness is associated with the recognition of the Other's subjective uniqueness, i.e. attachment to Europe is increasing with the more inclusionist understandings. As regards to the mean values the differences among the groups are statistically significant in all cases.

Table 5. The association between othering and Europeanness

\begin{tabular}{|c|c|}
\hline Groups & Mean values \\
\hline Exclusionist & 5.08 \\
\hline Ambivalent & 5.51 \\
\hline Inclusionist & 6.22 \\
\hline
\end{tabular}

Welch $=506.813 \mathrm{p}=0.000$

Post Hoc Test (Games-Howell)

Source: Author's own elaboration based on data from ESS8

Finally the value-based ontological foundations of these epistemologically relevant and praxis-related features should be explored. Just to remind, the paper assumes that those subjects who prefer the relative importance of values 
about diversity and self-transcendence, namely Universalism, Benevolence, and Self-direction, they are supposed to be rather inclusionist and more attached to Europe. The ESS is using the Portrait Value Questionnaire (PVQ) respective to the Schwartz-test in order to measure individual value-sets. PVQ is a 21 itemsbased survey proposes individual profiles with value-contents, and the respondents are perceiving on 1-6 scale, where ' 1 ' is 'very much like me' and ' 6 ' is 'not like me at all', how much they can identify themselves with the given descriptions. The paper then uses the centered scores of each profile-variable, which means that the individual preference of a certain value-content is calculated in comparison to the given subject's total average about the 21 items. In light of this, on Table 6 below 0 is the total average, and values with positive scores are preferred, while values with negative scores are dispreferred ones. Furthermore, for the adequate interpretation it is crucial to note that the individual understanding about the relative importance of a given value could be grasped not just through the preference of that certain value, but more by the intensity of this preference, i.e. by how much the value's score is higher than 0 .

Table 6. Relevant value-sets of each groups

\begin{tabular}{|c|c|l|c|c|c|}
\hline \multicolumn{2}{|c|}{ Exclusionist } & \multicolumn{2}{c|}{ Ambivalent } & \multicolumn{2}{c|}{ Inclusionist } \\
\hline Security & 0.6517 & Benevolence & 0.6169 & Benevolence & 0.8146 \\
\hline Benevolence & 0.4933 & Security & 0.5340 & Universalism & 0.6673 \\
\hline Universalism & 0.3355 & Universalism & 0.4088 & Self-direction & 0.5130 \\
\hline Tradition & 0.2711 & Self-direction & 0.3251 & Security & 0.2488 \\
\hline Self-direction & 0.1971 & Tradition & 0.1224 & Hedonism & -0.0374 \\
\hline Conformity & 0.0011 & Conformity & -0.1179 & Tradition & -0.0734 \\
\hline Achievement & -0.3251 & Hedonism & -0.2189 & Conformity & -0.3928 \\
\hline
\end{tabular}




\begin{tabular}{|c|c|c|c|c|c|}
\hline Hedonism & -0.3893 & Achievement & -0.3961 & Achievement & -0.4891 \\
\hline Power & -0.6277 & Stimulation & -0.6643 & Stimulation & -0.5125 \\
\hline Stimulation & -0.7754 & Power & -0.8144 & Power & -1.0720 \\
\hline
\end{tabular}

Source: Author's own elaboration based on data from ESS8

Table 6 justifies the paper's assumption respective to the value-based ontological foundations. As it is shown, in the inclusionist group the three top-preferred values are Benevolence, Universalism, and Self-direction with much higher scores than in the other two groups. As an oppositional tendency, scores of values about respecting traditional logics and semantics, such as Tradition and Conformity, as well as about the desire to control others from a superior status/position, like Power, are decreasing with the more inclusionist perceptions.

\section{CONCLUSIONS}

The paper both theoretically and empirically examined the interrelationship between the act of othering and the attachment to Europe, while it also addressed the value-based ontological foundations of these epistemologically relevant and praxis-related features. Late Modernity was proposed as a general framework that can hold together these components conceptually. The argument stressed that in our globalized/localized era of unfolding universalism/cosmopolitanism and reemerging particularism/traditionalism individual agents have to build up reflexive capacities and critical agencies since the collective logics and semantics as references are continuously shifting between de- and re-stabilization. Without reliable patterns subjects need to be open to the infinite, which means the acknowledgement of others' subjectivities (existential togetherness), the acceptance of 'both/and' understandings (antiessentialism), and the ascension to more all-embracing perspectives (pan- 
relationalism). Based on representative survey data the paper found out that perceptions about social inclusion and Europeanness are positively associated, while these ideational substances are ontologically supported by a certain subjective value-preference appreciates diversity and self-transcendence.

\section{ACKNOWLEDGEMENT}

Project no. PD124706 ('The Normative Actorness of the European Union') has been implemented with the support provided from the National Research, Development and Innovation Fund of Hungary, financed under the PD17 funding scheme.

\section{REFERENCES}

- Anderson, Benedict. 1983. Imagined Communities: Reflections on the Origin and Spread of Nationalism. London: Verso.

- Beck, Ulrich. 1992. Risk Society: Towards a New Modernity. London: Sage

- Beck, Ulrich. 1998. World Risk Society. Cambridge: Polity Press.

- Beck, Ulrich. 1999. What Is Globalization? Cambridge: Polity Press.

- Beck, Ulrich. 2005. Power in the Global Age. Cambridge: Polity Press.

- Beck, Ulrich. 2006. Cosmopolitan Vision. Cambridge: Polity Press.

- Beck, Ulrich and Grande, Edgar. 2007. Cosmopolitan Europe. Cambridge: Polity Press.7

- Beck, Ulrich and Beck-Gernsheim, Elisabeth. 1995. The Normal Chaos of Love. Cambridge: Polity Press.

- Beck, Ulrich and Beck-Gernsheim, Elisabeth 2002. Individualization: Institutionalized Individualism and its Social and Political Consequences. London: Sage. 
- Beck, Ulrich, Bonss, Wolfgang and Lau, Cristoph. 2003. The Theory of Reflexive Modernisation. Theory and Society 20 (2): 1-33.

- Beck, Ulrich, Giddens, Anthony and Lash, Scott. 1994. Reflexive Modernization. Politics, Tradition and Aesthetics in the Modern Social Order. Cambridge: Polity Press.

- Brons, Lajos. 2015. Othering, an Analysis. Transcience 6 (1): 69-90.

- Giddens, Anthony. 1984. The Constitution of Society. Outline of the Theory of Structuration. Cambridge: Polity.

- Giddens, Anthony. 1990. The Consequences of Modernity. Cambridge: Polity.

- Giddens, Anthony. 1991. Modernity and Self-Identity. Self and Society in the Late Modern Age. Cambridge: Polity.

- Giddens, Anthony. 1992. The Transformation of Intimacy: Sexuality, Love and Eroticism in Modern Societies. Cambridge: Polity.

- Giddens, Anthony. 1995. Politics, Sociology and Social Theory: Encounters with Classical and Contemporary Social Thought. Cambridge: Polity.

- Giddens, Anthony. 1999. Runaway World: How Globalization is Reshaping Our Lives. London: Profile.

- Schwartz, Shalom H. 2001. European Social Survey Core Questionnaire Development - Chapter 7: A Proposal for Measuring Value Orientations across Nations. London: European Social Survey, City University London.

- Schwartz, Shalom H. 1992. Universals in the Content and Structure of Values: Theory and Empirical Tests in 20 Countries. in Zanna, M (ed). Advances in Experimental Social Psychology (25). New York: Academic Press. 1-65.

- Schwartz, Shalom H. 2005. Basic Human Values: Their Content and Structure across Countries. in Tamayo, A. and Porto, J. B. (eds). Valores e comportamento nas organizaçoes, Petrópolis, Brazil: Vozes. 21-55.

- Schwartz, Shalom H. 2006. Basic Human Values: Theory, Measurement, and Applications. Revue française de sociologie 47 (4): 929-968.

- Schwartz, Shalom H. 2012. An Overview of the Schwartz Theory of Basic Values. Online Readings in Psychology and Culture 2 (1): 2-17. 